\title{
加硫天然ゴムに対するその理論式の適用*
}

\author{
村上謙吉** 草 野 孝: 衛** \\ 高野良好林火留宮弘灻林*
}

\section{Application of the Theory to Vulcanizates of Natural Rubber}

by

Kenkichi Murakami, Takae Kusano,

(The Chemical Research Institute of Non-Aqueous Solutions, Tohoku University, Sendai)

\section{Ryōkō Takano and Hiroyuki Kurumiya}

(Rubber Goods Inspection Association, Tokyo)

Four kinds of natural rubber were used for specimens, the kinds A, B and $\mathrm{G}$ were cured with sulphur and the kind D was cured with peroxide. The kinds A, B and C had different initial densities of crosslinking.

The actual density, $N_{0}$ for the four samples, was obtained by using the equation of $f(0)=N_{0}$ $R T\left(\alpha-\alpha^{-2}\right)$ and by the swelling method using the equation of Flory-Rhener.

According to the results obtained already, both the scissions of main chains and crosslink sites occurred at the same time for A, B and C, but the only main-chain scission occurred for the sample D.

The Eq. (1) was obtained for the sample D because $k=0$ in the Eq. (3) of

$$
\begin{gathered}
{\left[\frac{f_{t}}{f_{0}}=\left\{1-\frac{2 k}{M_{0}} \cdot q_{m}(t)\right\} \cdot e^{-\frac{x}{M_{0}} \cdot q_{m}(t)}+\frac{k}{M_{0}} \cdot q_{m}(t) \cdot e^{-\frac{2 x}{M_{0}} \cdot q_{m}(t)}\right] .} \\
\left(\begin{array}{c}
f_{t} \\
f_{0}
\end{array}\right)_{D}=e^{-\frac{x D}{M_{0}} \cdot q_{m}(t)}
\end{gathered}
$$

or

$$
q_{m}(t)=-N_{0},{ }_{D} \ln \left(\frac{f_{t}}{f_{0}}\right)_{D}
$$

As the Eq. (3) of $\left[\frac{f_{t}}{f_{0}}=\left\{1-\frac{2 k}{M_{0}} \cdot q_{m}(t)\right\} \cdot e^{-\frac{x}{M_{0}} \cdot q_{m}(t)}+\frac{k}{M_{0}} \cdot q_{m}(t) \cdot e^{-\frac{2 x}{M_{0}} \cdot q_{m}(t)}\right]$ is applicable to the samples of $\mathrm{A}, \mathrm{B}$ and $\mathrm{C}$, and $q_{m}(t)$ is equal to the four samples under the same condition, the Eq. (4) is established by substituting the Eq. (2) into the Eq. (3).

$$
-N_{0, D} \ln \left(\frac{f_{t}}{f_{0}}\right)_{D}=\frac{\left(\frac{f_{t}}{f_{0}}\right)_{A}-\left(\begin{array}{l}
f_{t} \\
\left.f_{0}^{-}\right)_{D}^{N_{0}, D}
\end{array}\right.}{\left(\frac{f_{t}}{f_{0}}\right)_{D}^{\frac{N_{0}, D}{N_{0}, A}}-2} \cdot \frac{M_{0}}{k_{A}} \cdot \frac{1}{\left(\frac{f_{t}}{f_{0}}\right)^{\frac{N_{0}, D}{N_{0}, A}}}
$$

Using the experimental data of $\left(\frac{f_{t}}{f_{0}}\right)_{A},\left(\frac{f_{t}}{f_{0}}\right)_{D}$ and the known value of $N_{0}, N_{A}, N_{D}$ and $M_{0}$, $k_{A}$ is calculated from the Eq. (4).

Similarly $k_{B}, k_{C}$ and $k_{D}$ are obtained.

(Received Feb. 23, 1967)

硫黄加硫天然ゴムで初期橋かけ密度 $N_{0}$ の異なるも の 3 種類， A, B， C を調製し，さらに，過酸化物加硫 天然ゴムDを調製した。乙れら $\mathrm{A} ， \mathrm{~B} ， \mathrm{C} ， \mathrm{D} 4$ 試料の 初期橋かけ密度 $N_{0}$ を, 未抽出の場合とアセトン抽出 後の場合上両者につき，(1)式の初期応力を実測して本

* 本報を「橋わけ高分子の化学レオロジー (第2報)」(Chemorheological Treatment of Crosslinked Polvmers, II) とする 原稿受理 昭和 42 年 2 月 23 日

** 東北大学非水溶液化学研究所 仙台市片平丁

*** コム製品愉查協会束京研究所 東京都黑时区束向鼠 4
式より求めた。

$$
f(0)=N_{0} R T\left(\alpha-\alpha^{-2}\right)
$$

ここで $R$ は気体定数, $T$ は測定温度, $\alpha$ は延伸率, $f(0)$ はこの際の応力である.

さらに, Flory-Rhener の式を利用して，膨潤法に よっても橋かけ密度を測定した。 とれらの結果を一括 して Table I に示す.

$$
x_{A}=103, x_{B}=94, x_{C}=130, x_{D}=123
$$

ただし， $N_{0} \times 10^{4} \mathrm{~mole} / \mathrm{cc}$ で表示してある. 
Table I. Grosslink density $N_{0}$ of various samples of vulcanized natural rubbers.

\begin{tabular}{|c|c|c|c|c|c|}
\hline \multicolumn{2}{|c|}{ Method of measurement } & \multirow{2}{*}{$\frac{A}{128}$} & \multirow{2}{*}{$\frac{B}{1.50}$} & \multirow{2}{*}{$\frac{C}{1.07}$} & \multirow{2}{*}{\begin{tabular}{|c|} 
\\
\end{tabular}} \\
\hline $\mathrm{E} \rho(\mathrm{l})$ & Unextracted $N_{0}^{\prime}$ & & & & \\
\hline $2 \mathrm{q}(1)$ & Extracted $N_{0}$ & 1.30 & 143 & 103 & 1.09 \\
\hline Swellıng & Unextracted $\nu_{S^{\prime}}$ & 107 & 1.22 & 0.78 & 092 \\
\hline
\end{tabular}

上表より膨潤法においては，やや低い橋かけ密度を 得ているが，てれは化学加硫以外の二次的結合の一部 が，(1)式の初期応力に影響を与えているのに対し，膨 潤法ではこの影響が少なく, 真の橋かけ密度に近い状 態を示しているためと思われる。しかしながら，ここ では, 便宜上, $N_{0}$ として抽出試料の初期応力から求 めた值を採用した。

A， B， C 亿主鎖，橋かけ両分子の同時切断が考えら れ，D試料では主鎖分子切断のみが考えられる。

こてで前報の(16)式を使用すると，D試料の場合は， $k=0$ であるから，(16)式は,

$$
\left(\frac{f_{t}}{f_{0}}\right)_{D}=e^{-\frac{x_{D}}{M_{0}} \cdot q_{m}(t)}
$$

あるいは,

$$
q_{m}(t)=-N_{0, D} \ln \left(\frac{f_{t}}{f_{0}}\right)_{D}
$$

さて， $\mathrm{A}$ 試料（あるいは $\mathrm{B} ， \mathrm{C}$ ）の硫黄加硫ゴムは， 橋かけ点抢よび主鎖分子の同時切断が考えられるので,
この場合の両切断確率の比を $k_{A}$ (あるいは $k_{B}, k_{C}$ ) と抢くと，前報の(16)式より，

$$
\begin{aligned}
\left(\frac{f_{t}}{f_{0}}\right)_{A} & =\left\{1-\frac{2 k_{A}}{M_{0}} \cdot q_{m}(t)\right\} \cdot e^{-\frac{x_{A}}{M_{0}} \cdot q_{m}(t)} \\
& +\frac{k_{A}}{M_{0}} \cdot q_{m}(t) \cdot e^{-\frac{2 x_{E}}{M_{0}} \cdot q_{m}(t)}
\end{aligned}
$$

ところが，D試料と $\mathrm{A}$ 試料とは同一天然ゴムを使用 しており，同一条件下の切断数 $q_{m}(t)$ は共通で等しい.

したがって，(3)式の $q_{m}(t)$ を(16)'式に代入すると(4)式 な得る。

$$
\begin{aligned}
-N_{0, D} \ln \left(\frac{f_{t}}{f_{0}}\right)_{D} & =\frac{\left(\begin{array}{l}
f_{t} \\
f_{0}
\end{array}\right)_{A}-\left(\frac{f_{t}}{f_{0}}\right)_{D}^{\frac{N_{0}, D}{N_{0}, A}}}{\left(\frac{f_{t}}{f_{0}}\right)_{D}^{\frac{N_{0} D}{N_{0}, A}}-2} \cdot \frac{M_{0}}{k_{A}} \cdot \\
& \frac{1}{\left(\frac{f_{t}}{f_{0}}\right)^{\frac{N_{0}, D}{N_{0}, A}}}
\end{aligned}
$$

(4)式において， $\left(f_{t} / f_{0}\right)_{A}$ および $\left(f_{t} / f_{0}\right)_{D}$ は䋧和実 験より求められ, Table II のとおりである.

(4)式より A，D両試料の緩和実験結果の Table II

\begin{tabular}{|c|c|c|c|c|c|c|c|c|}
\hline \multirow{2}{*}{$\underbrace{\text { Samp }}_{t(\mathrm{hr})}$} & \multicolumn{2}{|c|}{ A } & \multicolumn{2}{|c|}{ B } & \multicolumn{2}{|c|}{ C } & \multicolumn{2}{|c|}{ D } \\
\hline & $\begin{array}{c}N_{t} \times 10^{5} \\
(\mathrm{~mole} / \mathrm{cc})\end{array}$ & $\begin{array}{c}\left(f_{t} / f_{0}\right)_{A} \\
(\%)\end{array}$ & $\begin{array}{c}N_{t} \times 10^{5} \\
(\mathrm{~mole} / \mathrm{cc})\end{array}$ & $\begin{array}{c}\left(f_{1} / f_{0}\right)_{B} \\
(\%)\end{array}$ & $\begin{array}{c}N_{t} \times 10^{5} \\
(\text { mole } / \mathrm{cc})\end{array}$ & $\begin{array}{c}\left(f_{t^{\prime}}^{\prime} f_{0}\right) c \\
(\%)\end{array}$ & $\begin{array}{c}N_{t} \times 10^{5} \\
(\mathrm{~mole} / \mathrm{cc})\end{array}$ & $\begin{array}{c}\left(f_{t} / f_{0}\right) D \\
(\%)\end{array}$ \\
\hline 001 & 13.0 & 100 & 143 & 100 & 103 & 100 & 109 & 100 \\
\hline 1 & 830 & 638 & 110 & 772 & 8.34 & 81 & 10.1 & 924 \\
\hline 2 & 5.60 & 431 & 8.78 & 614 & 700 & 68 & 9.60 & 882 \\
\hline 3 & 3.80 & 292 & 705 & 493 & 567 & 55 & 9.15 & 840 \\
\hline 4 & 154 & 200 & 552 & 38.6 & 495 & 48 & 8.70 & 798 \\
\hline 5 & - & $\ldots$ & 490 & 343 & - & - & 843 & 773 \\
\hline 6 & - & - & - & - & 278 & 27 & 788 & 723 \\
\hline
\end{tabular}
のデータと Table I のデータとから $k_{A}$ が求まる. 同様にして, $k_{B}, k_{C}$ を求め, 乙れら $k$ 值の時間的変

\begin{tabular}{|c|c|c|c|c|c|c|c|}
\hline \multirow{2}{*}{$t(\mathrm{hr})$} & \multicolumn{3}{|c|}{$k$} & \multicolumn{3}{|c|}{$\begin{array}{l}Q_{n} t \times 10^{5} \\
(\mathrm{~mole} / \mathrm{cc})\end{array}$} & \multirow{2}{*}{$\frac{q_{m}(t) \times 10^{5}}{(\mathrm{~mole} / \mathrm{cc})}$} \\
\hline & $k_{i}$ & $k_{B}$ & $k_{C}$ & A & B & C & \\
\hline 05 & 328 & 175 & 57 & 130 & 079 & $\begin{array}{ll}0 & 17\end{array}$ & 076 \\
\hline 1 & 434 & 264 & 171 & 179 & 120 & 056 & 085 \\
\hline 2 & 463 & 291 & 194 & 3.08 & 212 & 1.02 & 137 \\
\hline 3 & 410 & 274 & 203 & 378 & 2.76 & 148 & 190 \\
\hline 4 & 341 & 256 & 186 & 4.06 & 3.35 & 1.76 & 246 \\
\hline 5 & - & 238 & - & - & 355 & - & 281 \\
\hline 6 & - & - & 182 & - & - & 248 & 354 \\
\hline
\end{tabular}
化を一括して示すと, Table III のようになる。 さらに, (3)式と $k$ 值から $q_{m}(t)$, 前報の(17)式から $Q_{c}(t)$ も訃算 できるのでてれらをまとめて Table III に示す.

Table II. The experimental values of relative stress vs. time.

Table III. The values of $k, Q_{c}(t)$ and $q_{m}(t) v s$. time.

昭和 42 年 7 月
前述のとおり, (16)式を使用する際は, $Q_{c}(t) /\left(N_{1} / 2\right) \leqq 1 / 5$ という条件があった。てれを考慮して検討すると， A， B， C，Dの 4 試料の緩和実験でだいたい数時間以内が， (16)式の成立する範用であることがわかる．Table III より， $k$ 值は最初の短時間を除いては, 各試料の埸合 だいたい一定值を示す。そして，A，B， Cいずれの試 料の場合も，橋かけ点切断優先の傾向を示している. (伊和141年11月25日 第15回レオロシー討論会にて溝演)

\section{参 考 文 献}

1）村上溓吉，川村三郎，辂野孝街，材料， 16, 478 (1967). 